\title{
Power Converters for Railguns
}

\author{
John A. Pappas \\ The University of Texas at Austin Center for Electromechanics \\ Dante E. Piccone \\ Silicon Power Corporation, Malvern, Pennsylvania
}

\begin{abstract}
The University of Texas at Austin Center for Electromechanics (UT-CEM) has been developing power converters for use with DC railguns. Special design rules have been established and demonstrated in the construction of laboratory hardware. Power converter requirements for electric guns are dependent on the characteristics of the power supply, load, circuit topology, and switching devices used. This paper discusses some of the design requirements particular to these converters and shows why simple figures of merit (FOMs) developed in the early design of a converter are not valid. An alternate FOM that can be used to compare converters and judge development progress is offered. Use of this FOM requires that an adequate amount of design work be completed on a converter before it is applied. The FOM is applied to previously demonstrated converters. Possibilities for near term development of devices and converters are examined and the potential results of that development are compared to past work by using the new FOM.
\end{abstract}

\section{INTRODUCTION}

$\mathrm{P}$ OWER converter requirements are dependent on the characteristics of the power supply, load, circuit topology, and switching devices. The discussion in this paper is limited to converters driving railguns that are powered by multiphase alternators. These systems are usually self-excited and have one or more high-power converters. There are several topology options in such systems. For example, the system may have a full-wave field excitation converter and a half-wave excitation converter. The system could also consist of two full-wave converters or two half-wave converters.

There are several features common to all topologies that affect the design of the converters and the choice of switching device: the converters control power flow during selfexcitation or load discharge and are used as inverters to recover excess magnetic energy at the end of the discharge; all of the systems operate at high rates of current rise, at significant voltage, at high current, and at high rates of energy transfer; the topologies of the system require that the converters are either line-commutated or the devices themselves are force-commutated. The design of the

Manuscript received December 21, 1999. This work was supported by the U.S. Army under contract DAA21-92-C-0105, The University of Texas at Austin, the Institute for Advanced Technology, and Parker Kinetic Designs, Inc. converters is further complicated by the fact that rotating machine designers favor high rotational speeds to increase energy storage density and increased number of poles to reduce stray magnetic fields and simplify force management. As a result, the electrical operating frequency of the systems is high compared to the typical operating frequency of high power, high voltage switching devices.

\section{DEVICE REQUIREMENTS}

Because of the high operating power of railgun converters, the devices considered in this paper will be limited to those that can carry several thousand amperes, can withstand and switch several thousand volts, and are available in a compact package. Devices that require substantial auxiliaries, have relatively short operating lives, or are orientation or vibration sensitive will not be considered. This eliminates most tube devices and smaller silicon power devices such as IGBT and other power transistors. Effectively then, the choice of devices lies between thyristors and certain sealed vacuum tube devices.

All of the systems considered here are line-commutated, which are generally favored by railgun system designers because of the additional circuitry and power required to use force-commuted or turn-off devices. While gate turn-off devices can operate at high di/dt, the high losses and low power transmission capability of GTO thyristors, as well as their additional trigger power requirements, make them compare unfavorably with line-commutated systems. Unsymmetrical devices, when used in line-commutated systems, require the addition of a recovering element such as a diode. The inclusion of an additional circuit element effectively doubles the mass of a power converter. Triggered vacuum switches meet most of the criteria listed above, but their current state of technology precludes their use at this time [1].

The criteria for choosing a switching device for use in a railgun converter are different than those for a continuousduty converter. Railgun power converters are operated in single or burst discharge modes. Also, a great premium is placed on minimizing the mass and volume of the converter. As a result, the ideal switch would operate at high voltage and current, switch on and off nearly instantaneously, and have very low conduction and switching losses.

In practice, these requirements are contradictory. Even though thyristors are constantly being improved, 
improvement in one characteristic is often made at the expense of another. In order to reach the operating voltages required in the power converters, devices are stacked in series. Therefore, one would expect that use of high voltage devices would result in fewer total devices in the system. Thyristor withstand voltage can be increased by surface contouring to reduce the external electric field, increasing (1) the resistivity of the wafer, (2) the minority carrier lifetime, or (3) wafer thickness. Most thyristors are properly contoured. Thicker thyristors have higher conduction power losses, deeper and longer recovery (increasing reverse recovery current, $\mathrm{I}_{\mathrm{rr}}$ and recovery time, $\mathrm{t}_{\mathrm{rr}}$ ), and require a longer turnoff time $\left(t_{q}\right)$. In addition, thicker devices tend to have lower critical rates of current rise. Increasing the carrier lifetime results in lower on-state loss and improves critical di/dt capability, but increases $t_{q}$ and decreases $d v / d t$ withstand capability [2].

The current rating of a device is really a limit on temperature rise. Although the peak current by itself does affect the recovery characteristics of an SCR [3], the peak current rating of a device is only applicable for steady-state operation at a specified operating frequency. Even the high current ratings published for pulsed-power SCRs are applicable only for the pulse length given. This rating is effectively the nonrepetitive one-cycle current rating $\left(\mathrm{I}_{\mathrm{FSM}}\right)$. For short-time duty, the allowable peak current is limited by the junction temperature rise that is a function of the switching and conduction power losses and of the effective conduction area of the device.

A generalized short-time rating for an SCR can be derived from the $\mathrm{I}_{\mathrm{FSM}}$ rating or the maximum on-state shorttime thermal rating for fusing $\left(\mathrm{I}^{2} \mathrm{t}\right)$. The $\mathrm{I}^{2} \mathrm{t}$ rating for a commercial device can usually be estimated by finding the integral of one current cycle with a peak at $\mathrm{I}_{\mathrm{FSM}}$. These ratings will give a reasonable approximation of maximum $\mathrm{I}^{2} t$ rating that can be withstood by a device as long as the critical di/dt rating is not violated. Within this limit, the rating is independent of current peak and pulse shape. Alternatively, the virtual junction temperature can be calculated by using finite element techniques or with the quasi 2-D method developed by Somos and Tobin $[4,5]$ and adapted for use in railgun power system design [6]. As an example of the utility of this method, the short time rating of an SPCO C784 SCR was calculated for a trapezoidal current shape at the specified $\mathrm{I}_{\mathrm{FSM}}$ of $24 \mathrm{kA}$. The result of the calculation is shown in Fig.1. The action represented by the current pulse is $2.9 \mathrm{MA}^{2} \mathrm{~s}$ and the resulting average virtual junction temperature rise was calculated to be $90 \mathrm{C}^{\circ}$. The maximum specified temperature for the device is $125^{\circ} \mathrm{C}$ and the maximum $\mathrm{I}^{2} \mathrm{t}$ is specified as $2.8 \mathrm{MA}^{2} \mathrm{~s}$. Both of these values vary from the calculation by a factor of 1.04 .

The $I^{2} t$ capability of an SCR varies with the square of the radius of the effective conduction area. However, large diameter devices are more difficult to turn on than small diameter devices because the plasma spreading velocity limits the rate at which a device can be turned on. Unless some provision is made to increase the critical di/dt of the device, turn-on effects rather than conduction heating will drive the converter design and the benefits of the increased diameter will not be realized. This problem has been addressed in GTO thyristors that employ highly interdigitated gates. Devices with critical rates of current rise in excess of $20 \mathrm{kA} / \mu \mathrm{s}$ are available commercially. However, the area occupied by gate conductor reduces the effective conduction area. In general, devices with highly interdigitated gate structures have less $\mathrm{I}^{2} \mathrm{t}$ capability than devices with standard gate structures. The aim, then, should be to optimize the critical di/dt capability with the action capability for a given device diameter and converter requirement.

Silicon Power Corporation (SPCO) has accomplished this optimization during a project to develop a device for railgun applications. The result, shown in Fig. 2, has been demonstrated at UT-CEM and by others [7] at over $3 \mathrm{kA} / \mu \mathrm{s}$ at low action and at 1 to $1.5 \mathrm{kA} / \mu \mathrm{s}$ at approximately $10 \mathrm{MA}^{2} \mathrm{~s}$. The device weighs $0.5 \mathrm{~kg}$ and has been operated at $5 \mathrm{kV}$. Its main drawback for use in high frequency converters is its $t_{q}$, which is approximately $300 \mu \mathrm{s}$.

\section{DEVICE COMPARISONS}

Often, designers desire to use FOMs to aid in the comparison and selection of devices. One figure of merit based on static characteristics is defined as

$$
\mathrm{FOM}_{1}=\frac{V_{R R M} I_{\text {rated }} t_{p k}}{\text { Effective conduction area }}
$$

The problem with this FOM is that it is based on transfer of charge rather than on junction temperature rise. In addition, normalizing the FOM by area ignores the advantage in converter packaging that can be gained by reducing the total number of devices through the use of large diameter devices. Furthermore, the FOM does not reflect the proper way to find the number of parallel paths due to conduction current in a converter. If the preliminary design is based on peak current, and the pulse width is longer than the specification, then too few devices will be specified. If the pulse width is shorter than specified, then the converter will be unnecessarily large.

Another way that a static FOM could be defined is by the maximum $\mathrm{I}^{2} t$, the reverse voltage and the device mass. This FOM is defined as

$$
\mathrm{FOM}_{2}=\frac{V_{R R M} \int i^{2} d t}{m}
$$

where $m$ is the mass of a device.

An advantage of $\mathrm{FOM}_{2}$ is that it includes (in the $\mathrm{I}^{2} \mathrm{t}$ rating) the effect of conduction losses due to differences in doping, gate structure and wafer resistivity. The problem with $\mathrm{FOM}_{2}$ is that it does not account for the dynamic characteristics of the devices under comparison. There is no provision for the important parameters $d i / \mathrm{dt}_{\mathrm{CRRT}}, \mathrm{t}_{\mathrm{q}}$, or $\mathrm{I}_{\mathrm{rr}} . \mathrm{I}_{\mathrm{rr}}$ is important to the converter design because it has a large effect on the size of the snubber circuit needed to protect the devices during turn-off. The turn-off time, $\mathrm{t}_{\mathrm{q}}$ is important to the design of the converter, but it should not be included in the FOM for comparison. The reason for omitting $t_{q}$ is simple. A device is not better or worse simply because of $t_{q}$. The turnoff time is either short enough for a specific application or it 
is not. Therefore, $t_{\mathrm{q}}$ should be used to cull devices before comparison. If $t_{q}$ is included in the FOM, then devices with higher voltage withstand capabilities may be eliminated even though their turn-off time is adequate. An FOM that includes all of the static and dynamic characteristics listed above can be defined as

$$
\mathrm{FOM}_{3}=\frac{V_{R R M} d i / d t_{c r i t} \int i^{2} d t}{I_{r r} m}
$$

In order to test the validity of the FOMs, nominal 500 and $2,000 \mathrm{~Hz}$ multiphase systems were designed to the preliminary stage. The design of the $500 \mathrm{~Hz}$ system includes estimates of the electromagnetic properties of the alternator and an electrical performance simulation. The $2 \mathrm{kHz}$ system design was extrapolated from the $500 \mathrm{~Hz}$ design by using the following assumptions:

- the number of poles in the alternator was increased by the ratio of the operating frequencies

- the operating voltage was assumed to be the same, even though increased commutation losses due to higher frequency operation and loss of coupling due to the increased number of poles would probably reduce the voltage delivered to the load

- the action produced by the alternator and passed through the converters was assumed to be the same because load performance determines the action requirement

- the rate of current rise was increased by the ratio of the operating frequencies

- the available turn-off time was reduced by the ratio of the operating frequencies

The operating requirements for each converter are listed in Table 1 . The values shown are per-phase for the worst-case phase.

The FOMs and number of switching devices required in the load converters for each system were calculated for several devices. The results are tabulated in Table 2. The numbers of devices required can be used as an indicator of the relative mass and volume of the load converters; however, there are other important factors that drive converter mass, such as device, snubber, and trigger size and mass. As can be seen, the FOMs bear little relationship to the numbers of devices required. This shows that the use of simple FOMs to judge switching devices for electric gun power converters is invalid, and that some level of design must be completed with each device under consideration before it can be considered for use.

\section{CONVERTER COMPARISONS}

A sensible FOM can be developed that can be used to measure progress in converter development and to compare converter designs. This FOM is based on the facts that (1) load performance is based on electrical action and (2) the converter voltage requirement is determined by the load requirements. Differences in numbers of phases and operating frequency are accounted for by including the total action passed, rather than by using a per-phase action. Turn-off time can be excluded for the reasons given above. Rate of current rise can likewise be ignored, because it is assumed that the converter is designed to withstand the worst-case $\mathrm{di} / \mathrm{dt}$ and because it must be assumed that projectile acceleration and $\mathrm{da} / \mathrm{dt}$ limits have not been exceeded. The FOM can be normalized by dividing by total converter mass, including clamps, heat sinks, protection and trigger circuits, and any other structures required. The FOM is defined as

$$
\mathrm{FOM}_{\mathrm{C}}=\frac{V_{\text {WITHSTAND }}\left[\int i^{2} d t\right]_{\text {TOTAL }}}{m}
$$

$\mathrm{FOM}_{\mathrm{C}}$ has been calculated for several demonstrated or designed systems and for one based on projected improvements in device performance and converter packaging technology, both of which are discussed below. $\mathrm{FOM}_{\mathrm{C}}$ for these systems is shown in Fig. 3.

\section{Future DeVices}

The device shown in Fig. 2 was designed for use in railgun power converters. The internal silicon junction assembly employs a unique light silicon sandwich (LSS) construction. Standard thyristors employ either traditional bonding methods to join the wafer to a refractory metal substrate or, more recently, use a dry contact technique that eliminates bonding and allows the silicon to float freely. The advantage of both the LSS and the dry contact methods is that they eliminate bowing due to mismatched material thermal expansion while cooling from high bonding temperature. Bowing becomes pronounced in large-area devices, making precise alignment during the photolithography process more difficult. The LSS concept (Fig. 4) uses equally thick sections of silicon alloyed to the top and bottom of a thin refractory metal, thus compensating adequately for thermal mismatch. The LSS has an advantage over the dry approach for pulse power applications because the anode is bonded to the metal and transient heat dissipation is improved (Fig. 5).

An early model of the LSS device was tested for use in the electric gun program [7]. The $125 \mathrm{~mm}$ device has an involute gate with no pilot. The device was triggered directly and required an unusually high gate current $(>400 \mathrm{~A})$. A new LSS thyristor that has a fully interdigitated gate was evolved from this version. This device was tested and showed significant improvement in performance [8]. A subsequent device, the SPT411, was manufactured with an interdigitated gate combined with a pilot. The new device requires a $20 \mathrm{~A}$ gate pulse and it performed as well as the device that required the larger gate pulse. The maximum test results for the SPT411 and the nonpilot device are shown in Table 3. Recovery tests were performed at the Army Research Laboratory (ARL) in Aberdeen, Maryland. The power circuit for the recovery tests was an under-damped RLC with $3.7 \mathrm{mF}$. The snubber used on the device was $100 \mu \mathrm{F}$ and $0.15 \Omega$.

The tests cited above are summarized in Fig. 6. The performance limitation was probably caused by dynamic avalanche, which results when a critical combination of reverse recovery current and voltage occurs. This phenomenon causes avalanching below the design voltage and subsequent current funneling [9]. This explanation was also supported by physics-based simulation [10] and by analysis that showed that no abnormal thermal or electrical 
stress was present that might explain the failures. In order to test the analysis, a special lower-recovery version of the SPT 411 was manufactured. Fig. 6 shows that an improvement was realized after the recovery current was reduced. However, the performance ceiling still exists. Thus, dynamic avalanche needs be recognized and better understood for pulse power applications that impose reverse voltage.

\section{FUTURE CONVERTER DESIGN}

Improved packaging efficiency can be achieved by using integrated composite clamping structures, the concept shown in Fig 7. The module consists of a four-parallel by threeseries array of switches. The switches are large-diameter, high voltage SCRs based on a near-term extrapolation of the SCR in Fig. 2. Snubbers are omitted for clarity. The composite clamp plate at each end is designed to include provisions for force distribution, thermal expansion, and device centering. Integrating these functions into a single component reduces the number of parts required and the length of the module. Preliminary design and analysis indicate that clamp mass will be reduced by $30 \%$ compared to present structures. In addition, two new device-packaging techniques, structured copper bonding and multilayer aluminum nitride (AIN) bonding are being developed by SPCO. Both of these methods entail eliminating the clamping requirement to maintain electrical contact.

The structured copper concept (Fig. 8) consists of a high-performance substrate that can be bonded directly to semiconductor devices. It is made of thousands of 10 to 12 mil strands of OFHC copper that form a compliant layer between the silicon device and the heat sink. Structured copper will significantly reduce the switch module thermal and electrical resistance by removing the dry interfaces between components. The structure's inherent compliance will mitigate the effect of the thermal stress caused by the different expansion rates of monolithic copper and silicon.

Another technique for device stacking and bonding is the use of a high thermal-conductivity multi-layer aluminum nitride cooler. The coefficient of thermal expansion (CTE) of AIN matches the CTE of silicon and can be easily used as a substrate material for SCR. The outside ceramic layers are covered with copper sheets using a well-established directbond copper technology. Multiple paths in the ceramic layer provide electrical conduction. This system has the added advantage of extremely low thermal resistance because the heat sink surface is bonded directly to the device. As a result, device packages constructed with this packaging technique will have an excellent surge-current response.

\section{ACKNOWLEDGEMENT}

The authors gratefully acknowledge the technical contributions to this work from Scott Pish and Peter Andryshak of UT-CEM, Bill Tobin and Chan Tieu of Silicon Power Corporation, and Hardev Singh and C. Hummer of the Army Research Laboratory.

\section{REFERENCES}

[1] J.A. Pappas, et al, "Characterization of triggered vacuum switches for high current operation," IEEE Trans Mag, Vol. 35, No.1, Jan 1999.

[2] D.R. Grafham, et al, General Electric SCR Manual, Prentice Hall, 1979.

[3] B.M. Bird, et al, An Introduction to Power Electronics, John Wiley and Sons, 1993.

[4] W.H. Tobin, "Effect of gate configuration on thyristor plasma properties", IEE IAS Conference Record, IEE IAS Annual Meeting, 1978.

[5] I.L. Somos,. et al "Two dimensional heat flow in a GTO having a highly interdigitated emitter". Proceedings $5^{\text {th }}$ annual IEEE Thermal and Temperature Symposium, 1989.

[6] Users Manual for SCR.f, Parker Kinetic Designs, Inc., unpublished, 1992.

[7] T.F. Podlesak, et al, "Single shot and burst repetitive operation of involute gate $125 \mathrm{~mm}$ symmetric thyristors up to $221 \mathrm{kA}$ with a di/dt of $2.0 \mathrm{kA} / \mu \mathrm{s}$ " Proceedings of the $12^{\text {th }}$ IEEE Pulse Power Conference, June 1999.

[8] H. Singh and C. R. Hummer "High action thyristors for pulse power applications" Proceedings of the $12^{\text {th }}$ IEEE Pulse Power Conference, June 1999.

[9] R.L. Pritchard, Electrical Characteristics of Transistors, McGraw Hill Book Co., NY, (1967), p. 135.

[10] T. Hansen, SPCO computer modeling using Medici Avanti commercial software.

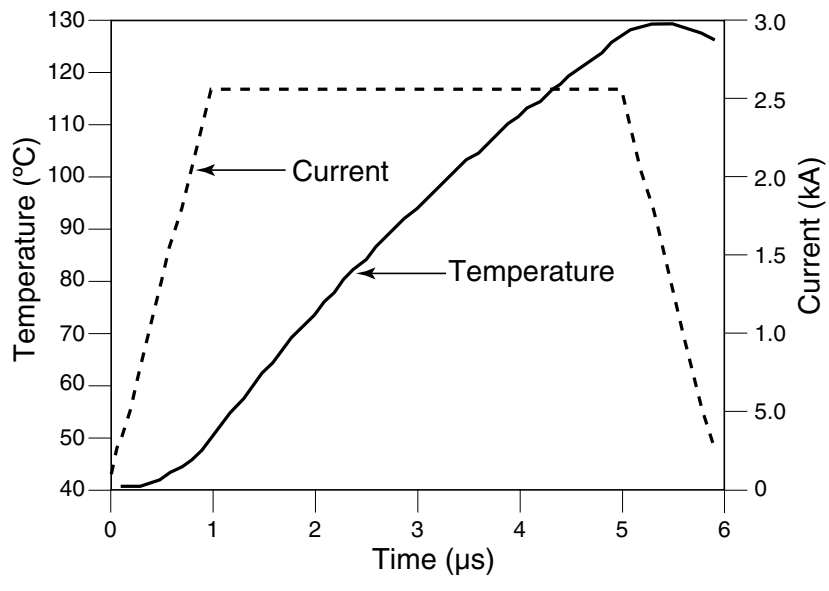

3910.1410

Fig. 1. Calculation of junction temperature from an arbitrary current pulse.

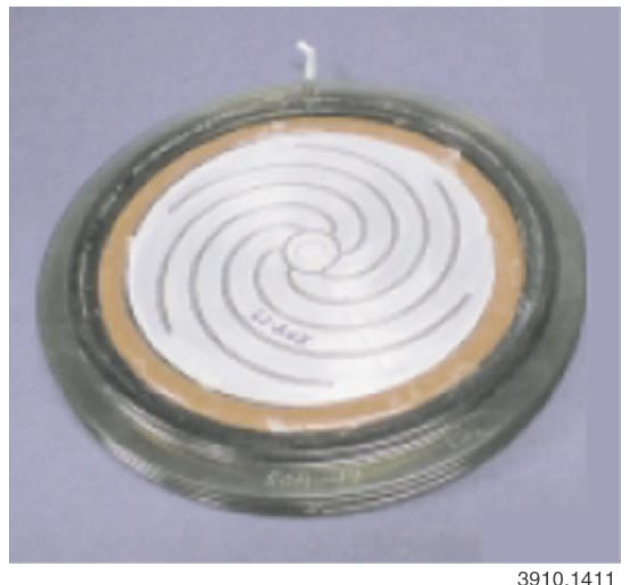

Fig. 2. SPCO 402B thyristor 
TABLE 1. OPERATING CHARACTERISTICS FOR TWO NOTIONAL ALTERNATORS.

\begin{tabular}{lcc}
\hline Operating Frequency & $500 \mathrm{~Hz}$ & $2,000 \mathrm{~Hz}$ \\
$\mathrm{I}^{2} \mathrm{t}$ & $6,800 \mathrm{MA}^{2} \mathrm{~s}$ & $6,800 \mathrm{MA}^{2} \mathrm{~s}$ \\
Peak di/dt & $7.5 \mathrm{kA} / \mathrm{s}$ & $30 \mathrm{kA} / \mathrm{s}$ \\
Maximum converter voltage & $8.5 \mathrm{kV}$ & $8.5 \mathrm{kV}$ \\
Minimum available turn-off time & $500 \mathrm{~s}$ & $125 \mathrm{~s}$ \\
\hline
\end{tabular}

TABLE 2. COMPARISON OF FIGURE-OF MERIT RESULTS WITH PRELIMINARY DESIGN CALCULATIONS.

\begin{tabular}{|c|c|c|c|c|c|c|c|c|c|c|c|}
\hline Man & $\begin{array}{l}\text { Device } \\
\text { Name }\end{array}$ & $\begin{array}{c}\text { FOM1 } \\
(\mathrm{J} / \mathrm{mm} 2)\end{array}$ & $\begin{array}{c}\text { FOM } \\
1 \\
\text { Rank }\end{array}$ & $\begin{array}{c}\text { FOM } \\
2 \\
(\mathrm{JA} / \mathrm{kg})\end{array}$ & $\begin{array}{c}\text { FOM } \\
2 \\
\text { Rank }\end{array}$ & $\begin{array}{c}\text { FOM } \\
3 \\
\text { (A2 } / \mathrm{Vg} \text { ) }\end{array}$ & $\begin{array}{c}\text { FOM } \\
3 \\
\text { Rank }\end{array}$ & $\begin{array}{c}\text { No. } \\
\text { Devices } \\
500 \mathrm{~Hz} \\
\text { System }\end{array}$ & $\begin{array}{c}500 \mathrm{~Hz} \\
\text { System } \\
\text { Rank }\end{array}$ & $\begin{array}{c}\text { No. } \\
\text { Devices } \\
2 \mathrm{kHz} \\
\text { System }\end{array}$ & $\begin{array}{c}\text { Nom } \\
2 \mathrm{kHz} \\
\text { System } \\
\text { Rank }\end{array}$ \\
\hline SPCO & SPT411 & $61.1 \times 10^{+6}$ & 7 & $150.0 \times 10^{+9}$ & 1 & $300.0 \times 10^{+15}$ & 1 & 352 & 1 & $\begin{array}{c}\text { na - tq } \\
\text { too long }\end{array}$ & 7 \\
\hline SPCO & SPT402B & $61.1 \times 10^{+6}$ & 7 & $150.0 \times 10^{+9}$ & 1 & $150.0 \times 10^{+15}$ & 2 & 352 & 1 & $\begin{array}{c}\text { na - tq } \\
\text { too long }\end{array}$ & 7 \\
\hline Px & TD2045 & $132.7 \times 10^{+6}$ & 4 & $23.2 \times 10^{+9}$ & 4 & $3.9 \times 10^{+15}$ & 5 & 720 & 3 & 2832 & 5 \\
\hline SPCO & C784 & $104.7 \times 10^{+6}$ & 5 & $6.3 \times 10^{+9}$ & 7 & $3.2 \times 10^{+15}$ & 6 & 800 & 4 & $\begin{array}{c}\text { na - tq } \\
\text { too long }\end{array}$ & 7 \\
\hline SPCO & C770 & $89.5 \times 10^{+6}$ & 6 & $10.4 \times 10^{+9}$ & 6 & $6.3 \times 10^{+15}$ & 3 & 936 & 5 & 3,600 & 6 \\
\hline $\mathrm{ABB}$ & 5SGA30J4505 & $45.8 \times 10^{+6}$ & 9 & $3.5 \times 10^{+9}$ & 9 & $1.7 \times 10^{+15}$ & 8 & 1,328 & 6 & 664 & 1 \\
\hline $\mathrm{ABB}$ & 5SGA30J4502 & $40.7 \times 10^{+6}$ & 10 & $2.8 \times 10^{+9}$ & 10 & $1.4 \times 10^{+15}$ & 9 & 1,488 & 8 & 744 & 2 \\
\hline $\mathrm{ABB}$ & 5SGA40L4501 & $31.7 \times 10^{+6}$ & 11 & $2.4 \times 10^{+9}$ & 11 & $1.2 \times 10^{+15}$ & 10 & 1,488 & 9 & 744 & 3 \\
\hline $\mathrm{ABB}$ & 5SGA30J2501 & $28.9 \times 10^{+6}$ & 12 & $2.2 \times 10^{+9}$ & 12 & $1.1 \times 10^{+15}$ & 11 & 2,044 & 10 & 1,022 & 4 \\
\hline $\mathrm{ABB}$ & 5STF08F2060 & $143.5 \times 10^{+6}$ & 3 & $3.8 \times 10^{+9}$ & 8 & $562.5 \times 10^{+12}$ & 12 & 2,808 & 7 & 3,600 & 6 \\
\hline $\mathrm{ABB}$ & 5STP52U5200 & $374.7 \times 10^{+6}$ & 1 & $49.1 \times 10^{+9}$ & 3 & $4.1 \times 10^{+15}$ & 4 & $\begin{array}{l}\text { na }- \text { tq } \\
\text { too long }\end{array}$ & 11 & $\begin{array}{c}\text { na - tq } \\
\text { too long }\end{array}$ & 7 \\
\hline $\mathrm{ABB}$ & $5 \mathrm{STP} 12 \mathrm{~N} 8500$ & $341.3 \times 10^{+6}$ & 2 & $18.5 \times 10^{+9}$ & 5 & $2.3 \times 10^{+15}$ & 7 & $\begin{array}{c}\text { na }- \text { tq } \\
\text { too long }\end{array}$ & 11 & $\begin{array}{c}\text { na - tq } \\
\text { too long }\end{array}$ & 7 \\
\hline na & Near Term SCR & $110.0 \times 10^{+6}$ & & $168.8 \times 10^{+9}$ & & $168.8 \times 10^{+15}$ & & 176 & & $\begin{array}{c}\text { na - tq } \\
\text { too long }\end{array}$ & \\
\hline
\end{tabular}

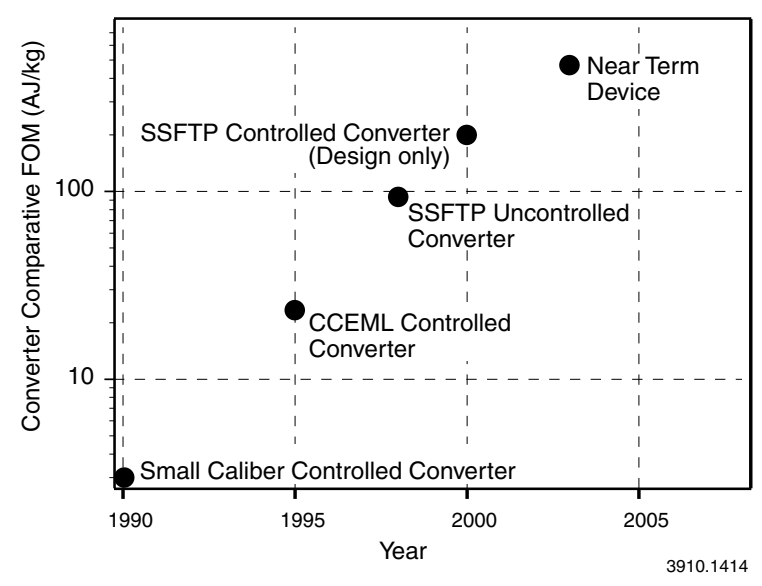

Fig. 3. Comparative FOM for load converters.

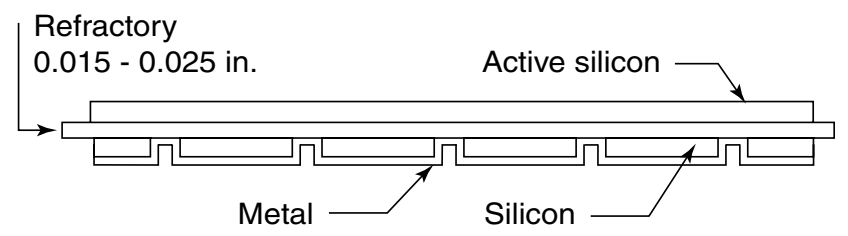

Silicon thicknesses matched for zero bow

3910.1415

Fig. 4. LSS concept with bonded surfaces. 


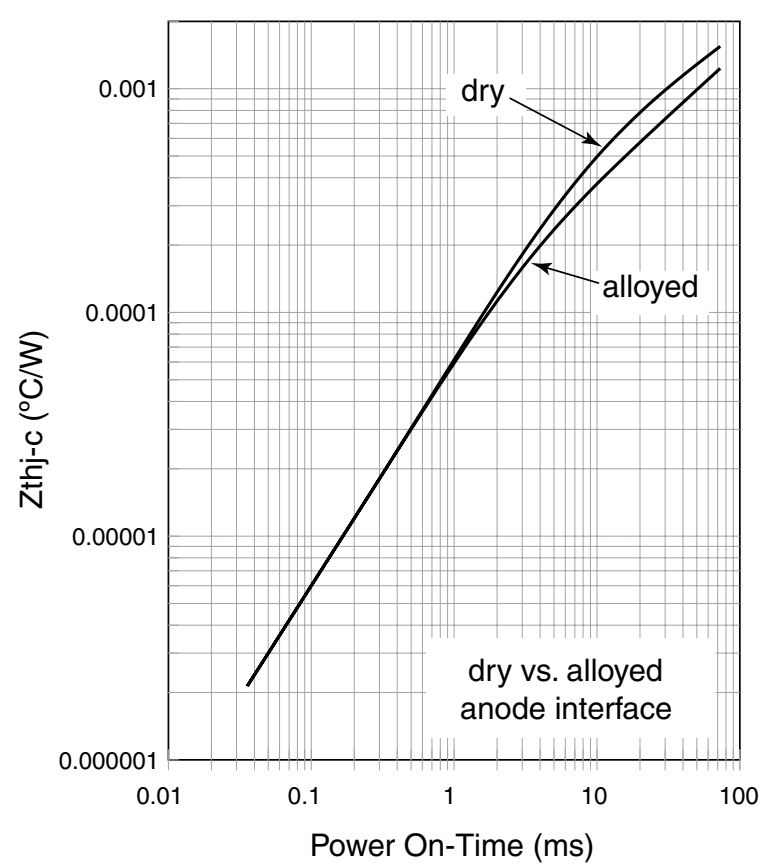

3910.1416

Fig. 5. Comparison of anode interface effect on thermal impedance.

TABLE 3. MAXIMUM TEST RESUlTS FOR SPT411

\begin{tabular}{lcccrc}
\hline \multicolumn{1}{c}{ Device Type } & Vdrm & Ipk & \multicolumn{1}{c}{ di/dt } & Vrrm & Irm \\
$(\mathrm{V})$ & $(\mathrm{kA})$ & $(\mathrm{A} / \mathrm{s})$ & \multicolumn{1}{c}{$(\mathrm{V})$} & \multicolumn{1}{c}{$(\mathrm{A})$} \\
\hline Pilot and No Pilot & 2,000 & 125 & 20,000 & 0 & \\
Pilot & 2,000 & 200 & na & 0 & \\
Pilot & 2,000 & 150 & 3,100 & 2,760 & 14,600 \\
Pilot, irradiated & 2,500 & 190 & 3,900 & 3,800 & 15,500 \\
\hline
\end{tabular}

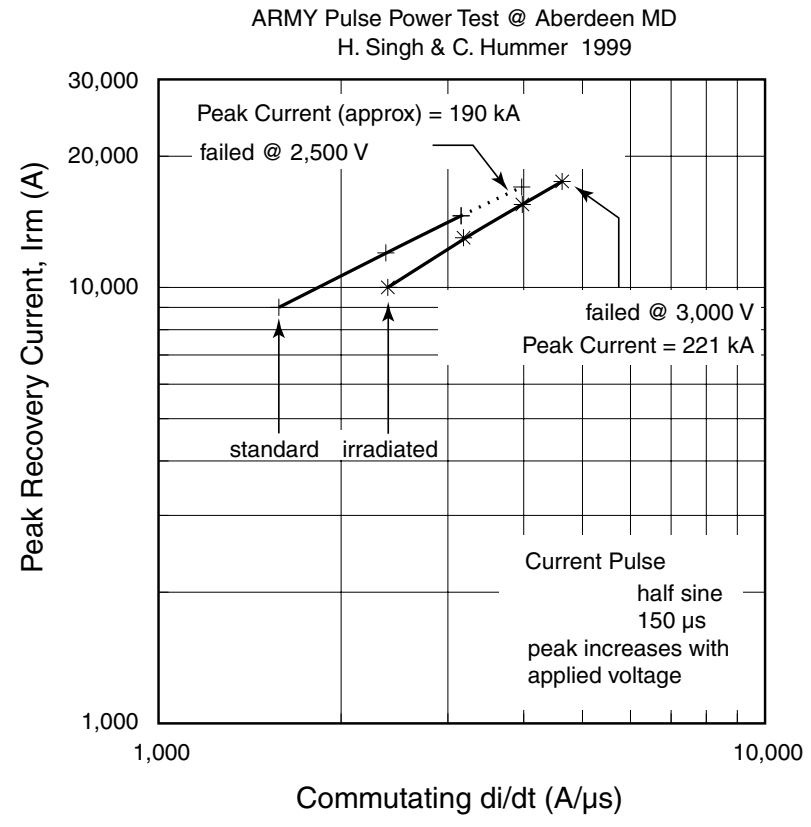

3910.1418

Fig. 6. Device test result showing evidence of a performance limitation.

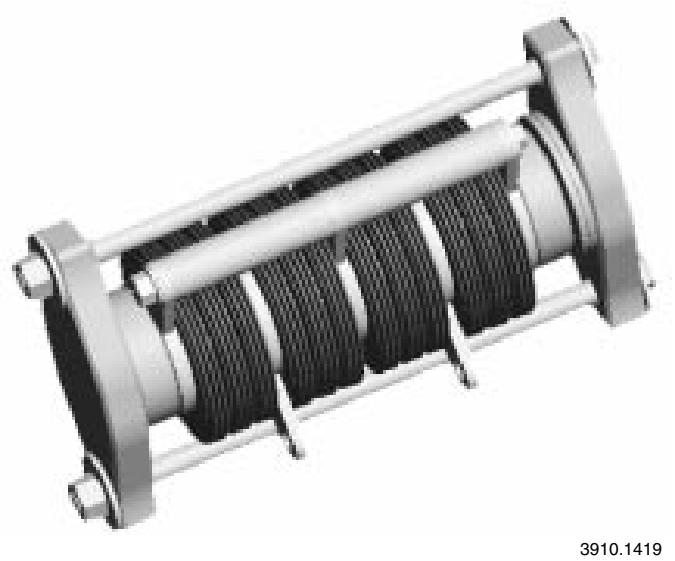

Fig. 7. Integrated-function clamp structure

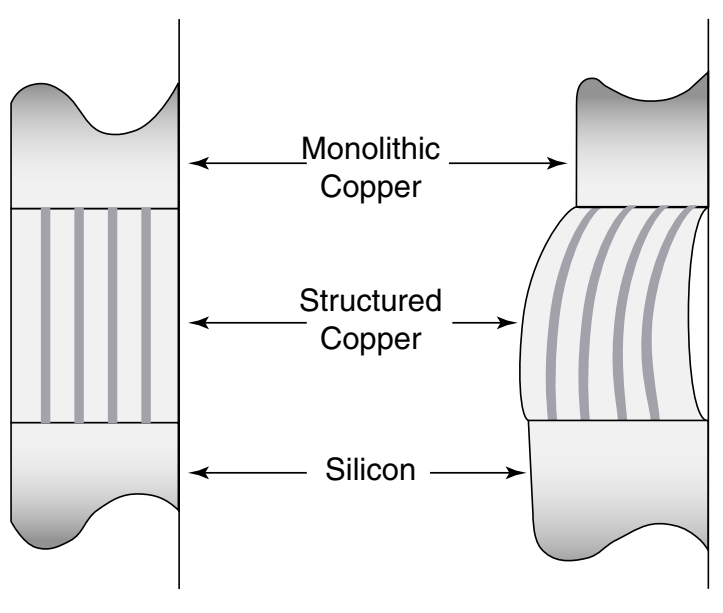

Fig. 8. Structured copper concept 